\title{
Efficacy of fluralaner in drinking water in controlling mite and improving welfare in laying hens
}

\author{
Dung T. Nguyen ${ }^{1}$, Ha H. Truong ${ }^{1}$, Nguyen T. N. Nguyen ${ }^{2}$, \\ Nam T. T. Nguyen ${ }^{1}$, \& Hien T. Le ${ }^{1 *}$ \\ ${ }^{1}$ Faculty of Animal Science and Veterinary Medicine, Nong Lam University, Ho Chi Minh City, Vietnam \\ ${ }^{2}$ MSD Animal Health Vietnam
}

ARTICLE INFO
Research Paper
Received: December 25, 2020
Revised: February 05, 2021
Accepted: February 22, 2021
Keywords
Behavior
Chicken
Exzolt
fluralaner
Mites
*Corresponding author
Le Thanh Hien
Email: hien.lethanh@hcmuaf.edu.vn

\begin{abstract}
The objective of the experiment was to evaluate the effectiveness of Exzolt (contaning fluralaner) to control mite and improve behavior relating to welfare in layers. Monitoring and recording indicators of livestock productivity, level of mite infection, number of eggs with red dots, and behavior of hens before and after using Exzolt were performed. 4 cameras to monitor hens' behavior from $18 \mathrm{pm}$ of the previous night to 6 am of the following morning were installed to record the layer's behavioral indicators caused by the mite including number of shakes, wing flaps, scratches, preening, bites, pecking (aggressive), before and after using Exzolt. As a result, the studied farm was heavily infected with mites with an average infection level of 1.79 on a scale of $0-2$. After the treatment with Exzolt, the farm became totally free of the mites in layers for many weeks thereafter. The use of Exzolt did not affect daily feed intake, mortality. The proportion of eggs with red spots decreased significantly. Especially, the layer's behavioral expression causing annoying was significantly reduced after using Exzolt. This is the reason for good recommendation to use this product to control mite for layer farm.
\end{abstract}

Cited as: Nguyen, D. T., Truong, H. H., Nguyen, N. T. N., Nguyen, N. T. T., \& Le, H. T. (2021). Efficacy of fluralaner in drinking water in controlling mite and improving welfare in laying hens. The Journal of Agriculture and Development 20(1), 31-38. 


\title{
Hiệu quả của fluralaner cung cấp qua đường uống trong việc kiểm soát mạt và cải thiện phúc lợi ở gà đẻ
}

\author{
Nguyễn Trung Dũng ${ }^{1}$, Trương Hồng Hà ${ }^{1}$, Nguyễn Thị Như Nguyện $^{2}$, \\ Nguyễn Thị Thu Năm ${ }^{1} \&$ Lê Thanh Hiền ${ }^{1 *}$ \\ ${ }^{1}$ Khoa Chăn Nuôi Thú Y, Trường Đại Học Nông Lâm TP.HCM, TP. Hồ Chí Minh \\ ${ }^{2}$ Công ty MSD Việt Nam
}

\section{THÔNG TIN BÀI BÁO}

Bài báo khoa học

Ngày nhận: 25/12/2020

Ngày chỉnh sửa: 05/02/2021

Ngày chấp nhận: 22/02/2021

Từ khóa

Exzolt

Fluralaner

Gà đẻ

Mạt

Tập tính động vật

*Tác giả liên hệ

Lê Thanh Hiền

Email: lethanh@hcmuaf.edu.vn

\section{TÓM TẮT}

Mục tiêu của đề tài là nhằm đánh giá hiệu quả diệt mạt của sản phẩm Exzolt (thành phần chính là fluralaner) và đồng thời giúp cải thiện phúc lợi trên gà mái đẻ. Tiến hành theo dõi và ghi nhận các chỉ tiêu về năng suất chăn nuôi, đánh giá mức độ nhiễm mạt, số lượng trứng có chấm đỏ, các biểu hiện về tập tính của gà mái trước và sau khi sử dụng thuốc Exzolt bằng việc quan sát qua camera. Kết quả cho thấy trại khảo sát nhiễm mạt rất nặng với mức độ nhiễm trung bình là 1,79 trên thang điểm 0 - 2. Sau liệu trình điều trị mạt bằng thuốc Exzolt, trại khảo sát đã không còn sự hiện diện của mạt trên gà mái đẻ, đồng thời hiệu quả của thuốc được tiếp tục duy trì và kéo dài nhiều tuần sau đó. Việc sử dụng thuốc diệt mạt Exzolt không ảnh hưởng đến lượng thức ăn ăn vào hằng ngày và tỷ lệ gà chết và loại thải. Tỷ lệ trứng có chấm đỏ giảm rõ rệt. Đặc biệt, các chỉ tiêu về tập tính gây khó chịu cho gà mái đẻ đều giảm xuống rõ rệt so với lúc chưa sử dụng thuốc diệt mạt. Đây là lý do khuyến cáo sử dụng sản phẩm này trong việc kiểm soát mạt trên gà đẻ.

\section{1. Đặt Vấn Đề}

Ngành chăn nuôi gia cầm tại Việt Nam đang ngày càng phát triển, nhiều trại chăn nuôi gà đẻ công nghiệp được đầu tư máy móc hiện đại và thực hiện đầy đủ quy trình vệ sinh sát trùng trong và ngoài trại. Những bệnh do vi khuẩn hay do vi rút được đặc biệt quan tâm bằng những biện pháp kiểm soát dịch bệnh nhưng thỉnh thoảng bệnh vẫn xảy ra và năng suất chăn nuôi cũng chưa được tối ưu. Một vấn đề quan trọng mà hầu như các trại chăn nuôi gà đẻ thường không quan tâm đến là mạt gà. Mạt gà có liên quan đến năng suất cũng như tình trạng sức khỏe của gia cầm.

Mạt gà (Dermanyssus gallinae) đã được mô tả trong nhiều thập kỷ là mối đe dọa lớn đối với ngành công nghiệp sản xuất trứng, gây ra những tác hại nghiêm trọng về sức khỏe và phúc lợi động vật (Mentz \& ctv., 2015). Đây là loại côn trùng hút máu, sống trong chuồng, xung quanh chuồng hoặc ký sinh ngay trên da của gà mái, từ đó dẫn đến các phản ứng tự nhiên của gà mái nhằm loại bỏ mạt ra khỏi cơ thể như: lắc mình, duỗi cánh, gãi đầu, rỉa lông, rỉa cánh,... quá trình này kéo dài sẽ khiến gà mái bị căng thẳng và tình trạng nhiễm mạt có thể cao đến mức dẫn đến thiếu máu và thậm chí gây chết. Sự phá hoại cũng có thể dẫn đến suy giảm chất lượng trứng (thông qua việc làm mỏng vỏ và đốm trên vỏ trứng) và suy giảm năng suất trứng (George \& ctv., 2015). Ngoài ra, mạt gà có thể đóng vai trò là một véc tơ truyền lây nhiều loại vi rút và vi khuẩn gây bệnh như bệnh ký sinh trùng máu, bệnh thương hàn, bệnh xoắn khuẩn. Gà nhiễm mạt được cho là giảm phúc lợi vì gia tăng tình trạng căng thẳng, từ đó làm cho gà dễ mắc bệnh hơn (Pham \& ctv., 2011) và hơn nữa nhiều báo cáo đã chỉ ra rằng mạt còn có thể tấn công vào các vật chủ khác, bao gồm cả con 
người, gây ra các tổn thương trên da. Trên người, thường bị mạt cắn ở bàn tay, cẳng tay, sau lưng hoặc trên cổ, tại nơi mạt cắn thường bị viêm da, ngứa dữ dội, nổi ban đỏ và có thể tìm thấy mạt tại những vùng bị tổn thương (Abdigoudarzi \& ctv., 2013).

Trên thực tế, việc điều trị mạt thật sự rất khó khăn, chi phí cao và thường không đạt hiệu quả cao. Các sản phẩm điều trị thường chỉ diệt được mạt chứ không diệt được trứng của chúng, vì vậy cần phải điều trị lần thứ hai, cách một vài ngày sau khi điều trị lần thứ nhất để hiệu quả diệt mạt cao hơn. Mặt khác, đa số các loại thuốc diệt mạt được sử dụng bằng cách phun, xịt và đây là đường cấp đã được chứng minh là có hiệu quả thấp đối với việc kiểm soát mạt vì có những con mạt có thể thoát khỏi khỏi điều trị do thuốc không đến được những kẽ hở, những khe nứt sâu nơi mạt ẩn nấp (Lima-Barbero \& ctv., 2020).

Với những lý do trên, nghiên cứu này được thực hiện nhằm mục đích tìm hiểu rõ hơn về ảnh hưởng của mạt đối với chăn nuôi gà đẻ, đồng thời đánh giá hiệu quả của thuốc diệt mạt của một sản phẩm dạng uống Exzolt (fluralaner) trong việc tiêu diệt mạt và những tác động tích cực của việc loại trừ mạt lên năng suất chăn nuôi và phúc lợi gà mái đẻ.

\section{Vật Liệu và Phương Pháp Nghiên Cứu}

\subsection{Vật liệu}

Nghiên cứu được thực hiện trên gà mái đẻ Isa Brown từ 45 tuần tuổi tại trại gà đẻ lâu năm ở khu vực Đông Nam Bộ. Trại được đánh giá là có hiện diện của mạt, và toàn bộ trại (10 ngàn gà) được khảo sát liên tục trong 2 tháng. Trong trại được lắp 4 carema quan sát. Đây là các camera hồng ngoại (có thể ghi hình trong điều kiện không có ánh sáng) lắp cố định và ghi hình liên tục trên hệ thống lưu trữ CCTV (Closed-circuit television). Vị trí lắp đặt camera trên thành chuồng nuôi gà hoặc trên nóc trại sao cho trong vùng quan sát của camera có thể theo dõi rõ được từ 3 lồng nuôi gà (mỗi chuồng nuôi từ 3 - 4 gà mái đẻ) (Hình 1 ). Video quan sát từ camera được ghi lại trong thẻ nhớ gắn trong camera. Để thực hiện việc phân tích video cần 1 máy vi tính, 1 thiết bị giúp máy vi tính có thể đọc được dữ liệu ghi trong thẻ nhớ.

Thuốc diệt mạt Exzolt được cung cấp bởi công ty MSD Animal Health Vietnam. Mỗi mL Exzolt chứa 10 mg fluralaner, dạng dung dịch, được cấp qua đường uống, sử dụng trong điều trị mạt trên gia cầm với liệu trình sử dụng là dùng hai lần liên tiếp, lần thứ hai cách lần thứ nhất 7 ngày. Liều lượng là $0,5 \mathrm{mg}$ fluralaner cho mỗi kg trọng lượng cơ thể gia cầm (tương đương $0,05 \mathrm{~mL}$ Exzolt).

\subsection{Phương pháp nghiên cứu}

\subsubsection{Khảo sát chăn nuôi tại trại}

Sau khi điều tra một số trại chăn nuôi gà đẻ, trại đang có vấn đề về mạt được chọn. Thực hiện hỏi và ghi nhận thông tin từ chủ nuôi, kết hợp với khảo sát thực tế tại trại và ghi nhận tất cả các số liệu về năng suất của trại trong quá trình chăn nuôi gồm năng suất trứng trên ngày, tỷ lệ đẻ trên ngày, số lượng trứng có những chấm đỏ trên vỏ rõ ràng, lượng thức ăn gà ăn vào trên ngày, số gà chết và loại 2 tuần trước và sau khi sử dụng uống thuốc diệt mạt Exzolt.

\subsection{2. Đánh giá mức độ nhiễm mạt}

Việc đánh giá mức độ nhiễm mạt được thực hiện tại 8 thời điểm: 1 ngày trước cấp thuốc lần thứ nhất, 1 ngày sau cấp thuốc lần thứ nhất, 1 tuần sau cấp thuốc lần thứ nhất, 1 tuần sau cấp thuốc lần thứ hai, 2 tuần sau cấp thuốc lần thứ hai, 3 tuần sau cấp thuốc lần thứ hai, 4 tuần sau cấp thuốc lần thứ hai, 5 tuần sau cấp thuốc lần thứ hai. Tổng số 43 con được chọn (tại nơi có đặt camera) để đánh giá mạt và cố định những con này cho toàn bộ khảo sát sự hiện diện của mạt trên gà.

Phương pháp của Stringham và ctv. (2003) dể đánh giá mức độ nhiễm mạt trên gà. Theo đó, bắt ngẫu nhiên 43 con gà phân bố đều trong chuồng có quan sát được bằng camera. Mỗi gà vạch lông kiểm tra mạt ở 3 vị trí: dưới gốc cánh, xung quanh hậu môn và lưng (vùng tiếp giáp 2 khớp hông đùi). Đếm số lượng mạt và ghi nhận điểm nhiễm như sau: "0" khi không có mạt hiện diện của mạt; "1" khi có $1-5$ con mạt $/ 1 \mathrm{~cm}^{2}$ bề mặt da - lông và "2" khi có trên 5 con mạt $/ 1 \mathrm{~cm}^{2}$ bề mặt da - lông. Hình 2 mô tả cách đánh giá mạt trên bề mặt da của gà.

\subsubsection{Phân tích video ghi hình từ camera}

Khoảng thời gian ghi hình của camera là từ 18 giờ ngày hôm trước đến 6 giờ sáng ngày hôm sau (thời gian tập tính thể hiện ít bị ảnh hưởng bởi yếu tố bên ngoài) nên chúng tôi sử dụng camera 


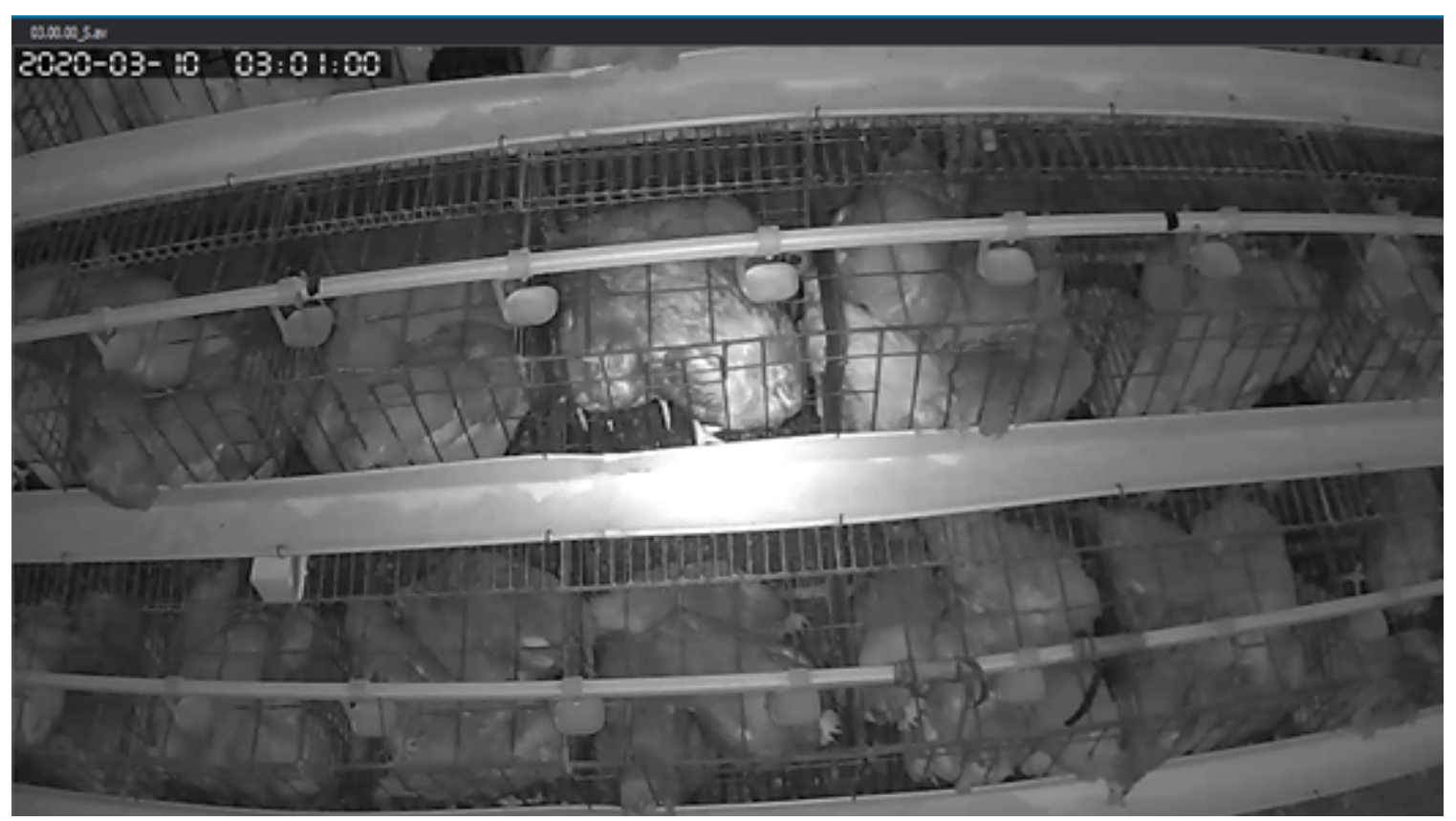

Hình 1. Hình chụp từ video ghi hình từ camera.

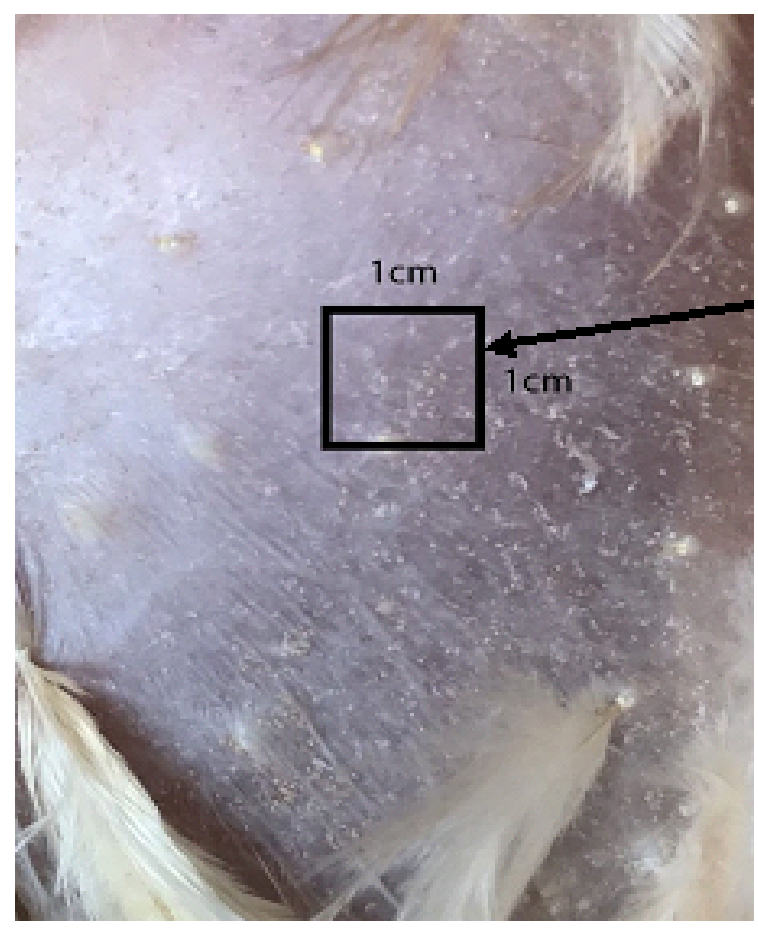

Hình 2. Đánh giá mức độ nhiễm mạt trên gà.

Trong $1 \mathrm{~cm} 2$ có nhiều hơn 5 con mạt, cho thấy gà nhiễm mạt ở mức độ 2 .

hồng ngoại để có thể quan sát được tập tính của gà mái đẻ vào ban đêm (khoảng thời gian trại không chiếu sáng). Đánh dấu những chuồng nuôi gà nằm trong vùng quan sát rõ nhất của camera bằng băng keo đen để phân biệt với những chuồng nuôi khác khi phân tích video ghi hình từ camera. Tổng số 43 gà trong 12 lồng nuôi, mỗi lồng 3 - 4 con, mỗi camera quan sát rõ được 3 lồng.

Lắc mình: gà đứng thẳng 2 chân, lông dựng đứng kết hợp với rung lắc cơ thể giúp loại bỏ mạt bám trên lông, da.

Duỗi cánh: gà đứng, 1 chân duỗi về phía sau, trong khi phần cánh cùng phía với chân đó cũng duỗi thẳng về phía sau cùng hướng với chân đang duỗi.

Gãi đầu: gà đứng thẳng, 1 chân đưa lên hướng đầu, dùng ngón chân gãi phần dưới mỏ hoặc trên đầu.

Rỉa lông, rỉa cánh: gà dùng mỏ rỉa lông ở những vùng mà mỏ gà có thể chạm tới được như lông phần lưng, cánh, đùi, ức,...

Cắn, mổ nhau: gà sử dụng mỏ mổ thẳng vào cơ thể gà khác, thường là phần đầu, cánh, hoặc há mỏ kẹp lấy phần da, thịt của gà khác kêt hợp với hành động kéo, dựt phần da, thịt đang kẹp được về phía mình. Vì các con trong cùng một lồng không thể phân biệt nên kết quả sẽ tính theo số lần có hành vi trong 1 đêm khảo sát trong lồng 4 con. Trong trường hợp lồng 3 con sẽ hiệu chỉnh trung bình con rồi hiệu chỉnh thành lồng 4 con. 


\subsubsection{Chỉ tiêu khảo sát}

Các chỉ tiêu về năng suất: thu thập các số liệu hằng ngày cho toàn trại về lượng thức ăn tiêu thụ, năng suất trứng, tỷ lệ đẻ, trọng lượng trứng, tỷ lệ chết và loại thải, trong 4 tuần theo hai giai đoạn: 2 tuần trước khi sử dụng thuốc diệt mạt và 2 tuần sau khi sử dụng thuốc diệt mạt. Số lượng trứng, tỷ lệ trứng có chấm đỏ trước và sau khi sử dụng thuốc diệt mạt.

Các chỉ tiêu về tập tính của gà: số lần lắc mình, số lần duỗi cánh, số lần gãi đầu, số lần rỉa lông/rỉa cánh, số lần cắn, mổ nhau trước và sau khi sử dụng thuốc diệt mạt. Mức độ nhiễm mạt trên gà theo 3 mức độ: 0,1 , và 2 , vào các thời điểm trước và sau khi cấp thuốc.

\subsubsection{Xử lý số liệu}

Các chỉ số về năng suất như lượng thức ăn trung bình, tỷ lệ chết và loại thải, tỷ lệ đẻ trứng, và tỷ lệ trứng có chấm đỏ được thu thập hằng ngày cho toàn trại và được coi là một giá trị quan sát. Các giá trị này được chia làm 2 nhóm: trước và sau khi sử dụng thuốc diệt mạt Exzolt. Trắc nghiệm $\mathrm{F}$ được dùng để so sánh trung bình của các chỉ tiêu này giữa 2 nhóm. Từ đó đánh giá hiệu quả của thuốc trên năng suất. Chỉ số mức độ nhiễm mạt đánh giá cho từng con được so sánh trước và sau khi sử dụng thuốc diệt mạt Exzolt bằng trắc nghiệm phi tham số (Kruskal Wallis). Tương tự, giá trị hành vi của gà mái đẻ theo các chuồng khảo sát được tính trung bình chung cho chuồng (4 gà mái). Số liệu mỗi ngày của từng camera được xem như một đơn vị khảo sát. Mô hình hồi quy hỗn hợp (biến phụ thuộc là từng số lần biểu hiện tập tính, biến độc lập là sử dụng thuốc - trước/sau, biến kết cự - cluster là thứ tự chuồng thu thập), được sử dụng để đánh giá tác động của việc sử dụng thuốc diệt mạt lên các biểu hiện vể tập tính của gà mái đẻ. Các xử lý phân tích này được tiến hành trên phần mềm STATA 14.2 (2017, College Station TX 77845, USA).

\section{Kết Quả và Thảo luận}

\subsection{Kết quả}

Ảnh hưởng của thuốc diệt mạt Exzolt đến các chỉ tiêu: lượng thức ăn ăn vào, tỷ lệ chết và loại thải, tỷ lệ đẻ và tỷ lệ trứng có chấm đỏ đườc trình bày trong Bảng 1. Thông qua xử thống kê, việc sử dụng thuốc diệt mạt Exzolt không ảnh hưởng đến lượng thức ăn ăn vào hằng ngày và tỷ lệ gà chết và loại thải trước và sau khi dùng thuốc $(P$ $>0,05)$. Tỷ lệ đẻ và tỷ lệ trứng có chấm đỏ trên vỏ theo ngày trong suốt quá trình khảo sát được trình bày trong Hình 3 .

Mức độ nhiễm mạt trên gà khảo sát theo tường thời điểm được trình bày trong Bảng 2 . Trong đó mạt đã giảm đáng kể đến 1 tuần sau cấp thuốc lần 2 không còn hiện diệt mạt trên gà. Kết quả này làm thay đổi các tập tính trên gà liên quan đến phúc lợi động vật. Phân tích video ghi hình từ 4 camera quan sát tập tính của 43 gà mái đẻ trong 12 lồng nuôi (mỗi một camera quan sát 3 lồng nuôi) về số lần lắc mình; số lần duỗi cánh; số lần gãi đầu; số lần rỉa lông, rỉa cánh; số lần cắn, mổ nhau, ở thời điểm trước và sau khi sử dụng thuốc diệt mạt Exzolt được thể hiện qua biểu đồ trong Hình 4. Tính chung cho khảo sát, những hành động tập tính này giảm đánh kể sau khi sử dụng thuốc có ý nghĩa về mặt thống kê $(P$ $<0,001$; Bảng 3).

\subsection{Thảo luận}

Trại khảo sát nhiễm mạt rất nặng với mức độ nhiễm trung bình là 1,79 trên thang điểm $0,1,2$. Sau liệu trình điều trị mạt bằng thuốc Exzolt gồm hai lần cấp thuốc cách nhau 7 ngày, trại khảo sát đã không còn sự hiện diện của mạt trên gà mái đẻ, đồng thời, hiệu quả của thuốc được tiếp tục duy trì và kéo dài nhiều tuần sau đó. Hinkle (2018) và Thomas (2018) đã chứng minh được khả năng diệt mạt của fluralaner trong Exzolt invitro lẫn invivo. Chưa có thử nghiệm tại Việt Nam, do đó đây có thể là những khảo sát lâm sàng đầu tiên đánh giá hiệu quả diệt mạt bằng đường uống.

Sau liệu trình sử dụng thuốc diệt mạt, tỷ lệ trứng có chấm đỏ giảm rất rõ rệt $(P<0,001)$, giảm 1,3 lần (từ $0,42 \%$ giảm còn $0,32 \%$ ) so với lúc chưa sử dụng thuốc diệt mạt Exzolt. Đây là loại trứng thường bị người thu mua ép giá. Theo Chauve (1998), tỷ lệ trứng có chấm đỏ liên quan mật thiết với tình trạng nhiễm mạt trên gà do chúng thường khu trú và hút máu tại vùng da lỗ huyện nên khi gà đẻ trứng sẽ tạo ra những chấm đỏ máu trên vỏ. Kết quả này thấy rõ hiệu quả giảm mạt trên gà.

Tất cả các chỉ tiêu khảo sát về tập tính của gà mái đẻ đều giảm xuống rõ rệt $(P<0,001)$ so với lúc chưa sử dụng thuốc diệt mạt. Từ đó, cho thấy hiệu quả vô cùng rõ rệt của thuốc diệt mạt 
Bảng 1. Ảnh hưởng của thuốc diệt mạt Exzolt đến các chỉ tiêu về lượng thức ăn ăn vào, tỷ lệ chết và loại thải, tỷ lệ đẻ và tỷ lệ trứng có chấm đỏ (tính trung bình trên 1.000 gà mái)

\begin{tabular}{lccc}
\hline Chỉ tiêu khảo sát & $\begin{array}{c}\text { Giai đoạn 14 ngày } \\
\text { trước dùng thuốc }\end{array}$ & $\begin{array}{c}\text { Giai đoạn 14 ngày } \\
\text { sau dùng thuốc }\end{array}$ & $\begin{array}{c}\text { Tính chung 28 } \\
\text { ngày khảo sát }\end{array}$ \\
\hline Thức ăn $(\mathrm{kg} / 1.000$ con) & $116,82 \pm 0,11$ & $118,34 \pm 0,11$ & $117,58 \pm 0,11$ \\
Chết và loại thải $(\%)$ & $0,34 \pm 0,01$ & $0,33 \pm 0,004$ & $0,34 \pm 0,01$ \\
Tỷ lệ đẻ $(\%)$ & $89,05 \pm 0,06$ & $86,38 \pm 0,07$ & $87,71 \pm 0,08$ \\
Tỷ lệ trứng chấm đỏ $(\%)$ & $0,42 \pm 0,001$ & $0,32 \pm 0,002$ & $0,37 \pm 0,002$ \\
\hline
\end{tabular}

Bảng 2. Bảng khảo sát mức độ nhiễm mạt của gà mái đẻ trước và sau khi sử dụng thuốc diệt mạt Exzolt

\begin{tabular}{lcccccc}
\hline \multirow{2}{*}{ Thời điểm khảo sát } & Số gà khảo sát & \multicolumn{5}{c}{ Mức độ nhiễm mạt ở trại $(\mathrm{con})$} \\
\cline { 3 - 7 } & $(\mathrm{con})$ & 0 & 1 & 2 & Trung bình & Trung vị \\
\hline 1 ngày trước cấp thuốc lần thứ nhất & 43 & 0 & 9 & 34 & 1,79 & 2 \\
1 ngày sau cấp thuốc lần thứ nhất & 43 & 0 & 26 & 17 & 1,40 & 1 \\
1 tuần sau cấp thuốc lần thứ nhất & 43 & 7 & 28 & 8 & 1,02 & 1 \\
1 tuần sau cấp thuốc lần thứ hai & 43 & 43 & 0 & 0 & 0 & 0 \\
2 tuần sau cấp thuốc lần thứ hai & 43 & 43 & 0 & 0 & 0 & 0 \\
3 tuần sau cấp thuốc lần thứ hai & 43 & 43 & 0 & 0 & 0 & 0 \\
4 tuần sau cấp thuốc lần thứ hai & 43 & 43 & 0 & 0 & 0 & 0 \\
5 tuần sau cấp thuốc lần thứ hai & 43 & 43 & 0 & 0 & 0 & 0 \\
\hline
\end{tabular}

Bảng 3. Trung bình các chỉ tiêu về tập tính của gà mái đẻ trước và sau khi sử dụng thuốc diệt mạt Exzolt (đơn vị: lần/ngày khảo sát/lồng 4 con)

\begin{tabular}{lcccc}
\hline Chỉ tiêu khảo sát & $\begin{array}{c}\text { Trung bình của 1 } \\
\text { tuần trước dùng } \\
\text { thuốc }\end{array}$ & $\begin{array}{c}\text { Trung bình của } 2 \\
\text { tuần sau dùng } \\
\text { thuốc }\end{array}$ & $\begin{array}{c}\text { \% so với } \\
\text { trước dùng } \\
\text { thuốc }\end{array}$ & $P$ \\
\hline Số lần lắc mình & 1,67 & 0,62 & 37,06 & $<0,001$ \\
Số lần duỗi cánh & 1,06 & 0,37 & 34,83 & $<0,001$ \\
Sồ lần gãi đầu & 12,71 & 5,94 & 46,72 & $<0,001$ \\
Số lần rỉa lông/rỉa cánh & 388,63 & 142,77 & 36,47 & $<0,001$ \\
Số lần cắn mồ nhau & 33,49 & 18,91 & 56,47 & $<0,001$ \\
\hline
\end{tabular}

Exzolt và ảnh hưởng rất tích cực từ việc sử dụng thuốc diệt mạt Exzolt đến phúc lợi của gà mái đẻ. Thomas (2019) cũng đã công bố tương tự về việc giảm các hành vi khó chịu của gà sau khi loại trừ mạt. Điều này không chỉ mang lại hiệu quả về góc độ phúc lợi động vật mà còn về năng suất vì gà không bị stress với những phiền toái này cũng như tiết kiệm được năng lượng cho sản xuất trứng hay nâng cao sức khác bệnh.

Về năng suất, tỷ lệ loại thải và lượng thức ăn ăn vào không có thay đổi đáng kể. Trong nghiên cứu này, không ghi nhận bất kỳ tác dụng phụ nào của việc sử dụng thuốc diệt mạt Exzolt dối với chất lượng của trứng và sức khỏe của gà mái đẻ. Chỉ có vấn đề về tỷ lệ đẻ. Tỷ lệ đẻ đạt đỉnh vào ngày 10 của khảo sát sau đó giảm dần, đến ngày khảo sát 14 (thời điểm sử dụng thuốc diệt mạt lần thứ nhất). Theo như dự tính của chúng tôi, sau khi sử dụng thuốc diệt mạt, gà mái đẻ sẽ giảm các biểu hiện của sự căng thẳng dẫn đến tỷ lệ đẻ sẽ bắt đầu tăng trở lại. Nhưng thực tế khảo sát, sau khi sử dụng thuốc, tỷ lệ đẻ tiếp tục giảm sâu, cho đến ngày 18 của khảo sát (4 ngày sau sử dụng thuốc lần 1). Mặc dù, chúng tôi đã rất cố gắng trong việc hạn chế các yếu tố có khả năng tác động xấu đến kết quả khảo sát nhưng vẫn không tránh khỏi việc một số yếu tố khách quan, cụ thể là yếu tố thức ăn ảnh hưởng và làm suy giảm tỷ lệ đẻ. Trong khoảng thời gian từ ngày 14 - 18 của khảo sát, thức ăn cung cấp từ nhà máy thay đổi, cám trở nên rất ướt, chất cám rất nát, ít lượng cám viên, khiến cho lượng cám ăn vào hằng ngày của gà mái giảm mạnh, dẫn đến tình trạng tỷ lệ đẻ giảm mạnh (nhưng vẫn giữ ở mức trên $80 \%$ ). Sau ngày 18 của khảo sát, thức ăn đã được ổn định trở lại, cùng với việc sử dụng 


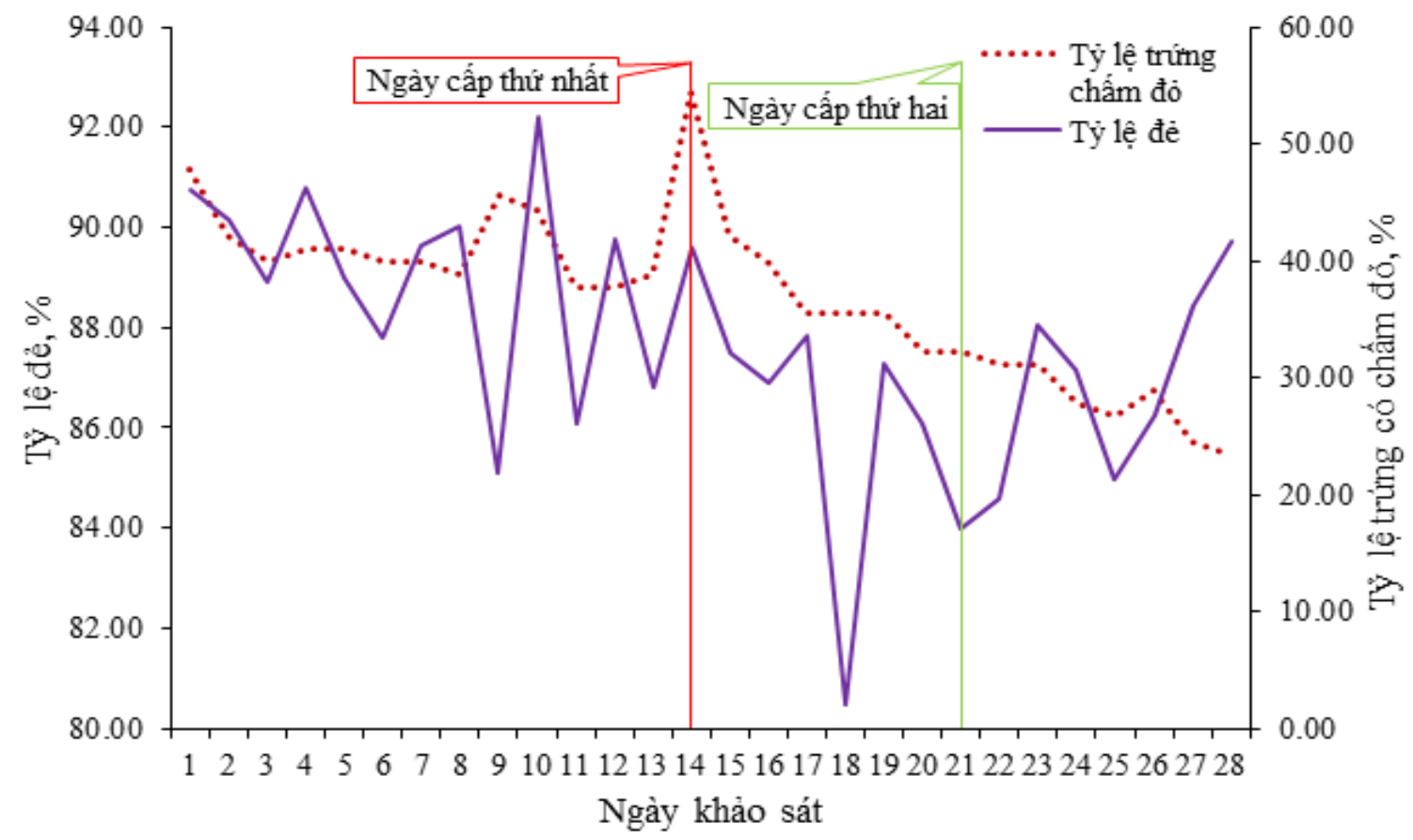

Hình 3. Tỷ lệ đẻ (\%) và tỷ lệ trứng có chấm đỏ (\%) tại trại khảo sát trước và sau khi sử dụng thuốc diệt mạt Exzolt.

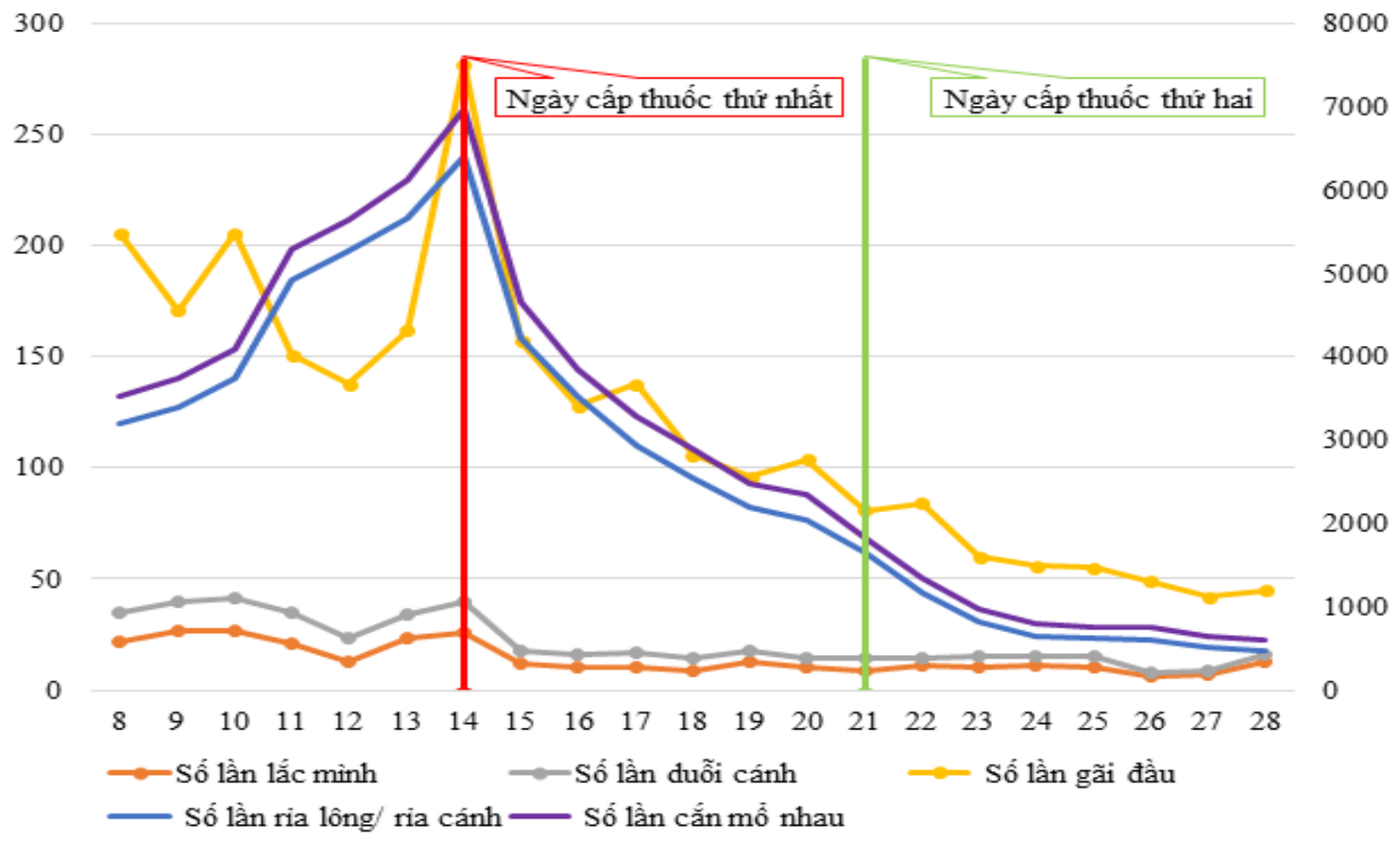

Hình 4. Sự thay đổi về tập tính của gà mái đẻ tại trại theo ngày khảo sát (trước và sau khi sử dụng thuốc diệt mạt Exzolt) (đơn vị: lần/ngày khảo sát/lồng 4 con) (trong đó giá trị Số lần rỉa lông/rỉa cánh sử dụng trục tung bên phải, còn các giá trị còn lại sử dụng trục tung bên trái). 
thuốc diệt mạt lần thứ hai theo liệu trình điều trị (vào ngày 21 của khảo sát) nhằm tiêu diệt toàn bộ mạt trong trại đã giúp tỷ lệ đẻ được cải thiện và tăng dần, phù hợp với tính toán của chúng tôi. Nếu kéo dài thời gian khảo sát, có lẽ năng suất đẻ sẽ ổn định và cải thiện hơn. Một điều rõ ràng là sau khi sử dụng thuốc lần thì năng suất trứng vẫn tiếp tục tăng, điều đó cho thấy việc sử dụng thuốc không có ảnh hưởng xấu đến khả năng đẻ của gà.

\section{Kết Luận}

Nghiên cứu thực địa cho thấy việc sử dụng thuốc diệt mạt Exzolt để điều trị mạt là có hiệu quả, thời gian tác động của thuốc rất nhanh và hiệu quả tiêu diệt mạt của thuốc còn kéo dài nhiều tuần sau đó. Bên cạnh đó, thuốc còn tác động tích cực đến việc nâng cao năng suất chăn nuôi và cải thiện rõ rệt các hành vi của gà đẻ liên quan đến phúc lợi động vật trong chăn nuôi.

\section{Tài Liệu Tham Khảo (References)}

Abdigoudarzi, M., Mirafzali, M. S., \& Belgheiszadeh, H. (2013). Human infestation with Dermanyssus gallinae (Acari: Dermanyssidae) in a family referred with pruritus and skin lesions. Journal of Arthropod Borne Diseases 8(1), 119-123.

Chauve, C. (1998). The poultry red mite Dermanyssusgallinae (De Geer, 1778): Current situation andfuture prospective for control. Veterinary Parasitology 79(3), 239-245.

George, D. R., Finn, R. D., Graham, K. M., Mul, M. F., Maurer, V., Moro, C. V., \& Sparagano, O. A. E. (2015). Should the poultry red mite Dermanyssus gallinae be of wider concern for veterinary and medical science? Parasites \& Vectors 8, 178.
Hinkle, N. C., Jirjis, F., Szewczyk, E., Sun, F., \& Flochlay-Sigognault, A. (2018). Efficacy and safety assessment of a water-soluble formulation of fluralaner for treatment of natural Ornithonyssus sylviarum infestations in laying hens. Parasites Vectors 11, 99.

Lima-Barbero, J. F., Villar, M., Hofle, U., \& de la Fuente, J. (2020). Challenges for the control of poultry red mite (Dermanyssus gallinae). In Bastidas Pacheco, G. A. (Ed.). Parasitology and Microbiology Research. London, UK: IntechOpen.

Mentz, M. B., Silva, G. L., \& Silva, C. E. (2015). Dermatitis caused by the tropical fowl mite Ornithonyssus bursa (Berlese) (Acari: Macronyssidae): a case report in humans. Revista da Sociedade Brasileira de Medicina Tropical 48(6), 786-788.

Pham, S. L., Nguyen, B. H., Tran X. H., Nguyen, H. H., Huynh, T. M. L., Le, N. M., Pham, Q. T., Pham, N. T., Do, N. T., \& Nguyen, V. T. (2011). Poultry disease in Vietnam. Ha Noi, Vietnam: Agricultural Publishing House.

Stringham, M., \& Watson, W. (2003). Fowl mite management in breeders. The Proceedings of the 2003 Broiler Breeder and Hatchery Management Conference (8). Statesville, North Carolina: North Carolina State University Cooperative Extension Service.

Thomas, E, Temple, D., \& Petersen, I. (2019). Effect of fluralaner on behavioural stress indicators in laying hens infested with Dermanyssus gallinae. The $4^{\text {th }}$ International Symposium on Parasite Infections in Poultry (36-37). Vienna, Austria: World Veterinary Poultry Association.

Thomas, E., Zoller, H., Liebisch, G., Alves, L. F. A., Vettorato,. L., Chiummo, R. M., \& Flochlay, A. S. (2018). In vitro activity of fluralaner and commonly used acaricides against Dermanyssus gallinae isolates from Europe and Brazil. Parasites Vectors 11, 361. 